\title{
Isothermal Phase Transformations and Stability of Retained Austenite during Quenching and Partitioning Process for 0.15C Steel
}

\author{
Jong-Won Jin*, Chulho Park** and Namhyun Kang**,† \\ *Quality Control Team, Hyundai Steel, Dangjin, Chungnam 31719, Korea \\ **Department of Materials Science and Engineering, Pusan National University, Busan 46241, Korea \\ †Corresponding author : nhkang@pusan.ac.kr \\ (Received January 26, 2017 ; Revised February 6, 2017 ; Accepted February 6, 2017)
}

\begin{abstract}
The microstructure and dilatation for $0.15 \mathrm{C}$ steels were investigated to define the phase transformation during the quenching and partitioning (Q\&P) process. For the one step Q\&P dilatation, the isothermal martensite/bainite transformation occurred because the holding temperature was between $M_{s}$ and $M_{f}$. The isothermally transformed martensite/bainite and the athermally transformed martensite were produced by a loss of retained austenite. As the holding time increased, new martensite-start $\left(M_{s}\right)$ temperature produced from the final quenching process decreased due to the carbon partitioning from the martensite to the retained austenite. This was the direct evidence of increment for the retained austenite stability. For the two step Q\&P dilatation, the isothermal bainitic transformation occurred because the partitioning temperature was larger than the $\mathrm{M}_{\mathrm{s}}$ and new $\mathrm{M}_{\mathrm{s}}$. The partitioning at $400^{\circ} \mathrm{C}$ indicated the short incubation period for the bainite transformation than the $350^{\circ} \mathrm{C}$ partitioning because the partitioning at $400^{\circ} \mathrm{C}$ should acquire the larger thermal driving force for carbon partitioning than the $350^{\circ} \mathrm{C}$ partitioning. A quick drop of $\mathrm{M}_{\mathrm{s}}$ and short period of bainite incubation for the $400^{\circ} \mathrm{C}$ partitioning steel were also the direct evidence of significant effects of carbon partitioning on the stability of retained austenite.
\end{abstract}

Key Words : Retained austenite, Partitioning, Isothermal martensite transformation, Bainite transformation, Carbon diffusion

\section{Introduction}

Many types of automobile sheet steels have been studied to acquire an increasing demand; high strength and elongation. Development of quenching and partitioning (Q\&P) steels is also underway to satisfy the demand. In modern times, Q\&P process is applied to ferritic and martensitic stainless steels ${ }^{1,2)}$. The Q\&P steel is normally composed of carbon-depleted martensite and carbon-enriched retained austenite. The hard microstructure (martensite) is produced by the initial quenching to a temperature between martensite-start $\left(\mathrm{M}_{\mathrm{s}}\right)$ and martensite-finish $\left(\mathrm{M}_{\mathrm{f}}\right)$ temperatures following the full austenization or intercritical annealing. And, it is subsequently heat-treated through two different processes: (i) holding at the initial quenching temperature (one step Q\&P), (ii) partitioning at a higher temperature than the initial quenching temperature (two step Q\&P) ${ }^{3)}$. Consequently, the Q\&P steel exhibits transformation- induced plasticity (TRIP) phenomenon due to the existence of carbon-enriched and stabilized austenite. Bainite and new martensite can be obtained from the unstabilized austenite during the partitioning and the final quenching step, respectively ${ }^{4,5)}$. Furthermore, the Q\&P steels produced the carbide precipitates delaying/ prohibiting the stabilization of the retained austenite ${ }^{6}$.

There are the other phase transformations observed for the Q\&P steels such as isothermal martensite transformation $^{7,8)}$ and bainitic ferrite transformation ${ }^{9)}$. These phase transformations influence the amount and stabilization of the retained austenite. The stability of the retained austenite was studied in a $0.09 \mathrm{C}$ steel by measuring the variation of new $M_{s}$ temperature ${ }^{10)}$. The isothermal martensite transformation occurs normally in high carbon steels ${ }^{11)}$. For a low carbon $(0.15 \mathrm{C}$ wt.\%) 
Q\&P steel, Kim et al. found the isothermal martensite transformation/bainite transformation as a function of partitioning temperature and time ${ }^{12)}$. However, the isothermal martensite and bainite transformation were not exactly defined in their study. Specifically, the changes of microstructures are not investigated with the stability of retained austenite for Q\&P steels.

The objective of the study is to identify the isothermal martensite/bainite transformations and its effect on the retained austenite during the partitioning (one step Q\&P and two step Q\&P) processes by measuring a dilatation and microstructural behavior. Furthermore, this study will be important to understand and estimate the microstructural evolution of the weldment and heat affected zone $^{13,14)}$

\section{Experimental procedure}

A cold-rolled steel sheet was used for phase transformation analysis. The steel had a composition of Fe-0.15C1.48Si-1.5Mn (wt.\%). Heat treatment conditions were selected by considering $\mathrm{Ac}_{1}, \mathrm{Ac}_{3}$, and $\mathrm{M}_{\mathrm{s}}$ temperatures which were estimated from the available equations ${ }^{15,16)}$. The $\mathrm{Ac}_{1}$ and $\mathrm{Ac}_{3}$ temperatures were mostly the same as compared with Thermo-Calc software. An intercritical annealing temperature to have a phase fraction $(\alpha: \gamma=$ 25 : 75) was set to $885^{\circ} \mathrm{C}$ using Thermo-Calc software.

$$
\begin{aligned}
\mathrm{Ac}_{1}\left({ }^{\circ} \mathrm{C}\right) & =723-10.7 \mathrm{Mn}+29.1 \mathrm{Si}=760{ }^{\circ} \mathrm{C} \\
\mathrm{Ac}_{3}\left({ }^{\circ} \mathrm{C}\right) & =910-203\left(\mathrm{C}^{1 / 2}\right)+44.7 \mathrm{Si}=898^{\circ} \mathrm{C} \\
\mathrm{M}_{\mathrm{s}}\left({ }^{\circ} \mathrm{C}\right) & =539-423 \mathrm{C}-30.4 \mathrm{Mn}-7.5 \mathrm{Si}+30 \mathrm{Al} \\
& =403{ }^{\circ} \mathrm{C}
\end{aligned}
$$

An initial quenching temperature was determined to produce the most retained austenite by Koistinen Marburger relationship ${ }^{17)}$.

$$
\begin{aligned}
\mathrm{f}_{\mathrm{m}}(\%)= & \left(1-\mathrm{e}\left\{-0.011\left(\mathrm{M}_{\mathrm{s}}-\mathrm{QT}\right)\right\}\right) \\
& \mathrm{x} \% \gamma(\text { at annealing temperature })
\end{aligned}
$$

where $f_{m}$ is the volume fraction of a martensite produced from the initial quenching, QT is the initial quenching temperature, and $\% \gamma$ is the volume fraction of an austenite at the intercritical annealing temperature. Dilatometry specimens were fabricated to the size $(1 \times 3 \times 10 \mathrm{~mm})$ and the intercritical annealing was executed at $885^{\circ} \mathrm{C}$ for 270 seconds, followed by quenching to the room temperature (cooling rate $\sim 40^{\circ} \mathrm{C} / \mathrm{s}$ ). Dilatation conditions for phase transformation analysis are shown in Table 1. Ht denotes the holding time following the initial quenching, PT the partitioning temperature, and Pt the partitioning time. Heating and cooling rates for
Table 1 Dilatation conditions for quenching and partitioning process

\begin{tabular}{|c|c|c|c|c|}
\hline & $\begin{array}{c}\text { QT } \\
\left({ }^{\circ} \mathrm{C}\right)\end{array}$ & $\mathrm{Ht}(\mathrm{s})$ & $\mathrm{PT}\left({ }^{\circ} \mathrm{C}\right)$ & $\mathrm{Pt}(\mathrm{s})$ \\
\hline $\begin{array}{c}\text { One step } \\
\text { Q\&P }\end{array}$ & 240 & $\begin{array}{c}3,5,10, \\
20,30\end{array}$ & - & - \\
\hline $\begin{array}{c}\text { Two step } \\
\text { Q\&P }\end{array}$ & 240 & 5 & 350,400 & $\begin{array}{c}1,5,10,30, \\
100,1000\end{array}$ \\
\hline
\end{tabular}

Q\&P dilatation test were the same as the continuous cooling dilatation. The microstructures of the samples were investigated using light optical microscopy (LOM) and scanning electron microscopy (SEM). The samples used in the LOM and SEM analyses were etched with $2 \%$ nital and sodium metabisulfite $\left(\mathrm{Na}_{2} \mathrm{~S}_{2} \mathrm{O}_{5}+\mathrm{H}_{2} \mathrm{O} 100 \mathrm{ml}\right)$.

\section{Result and discussion}

Fig. 1 shows the dilatation behavior of continuous heating and cooling from the intercritical annealing temperature $\left(885^{\circ} \mathrm{C}\right)$. An epitaxial ferrite (red circle in Fig. 1a) and a martensite (blue circle in Fig. 1a) were formed from the austenite during quenching at $630 \sim 780^{\circ} \mathrm{C}$ and $101 \sim 300^{\circ} \mathrm{C}$, respectively. It is normally assumed that a

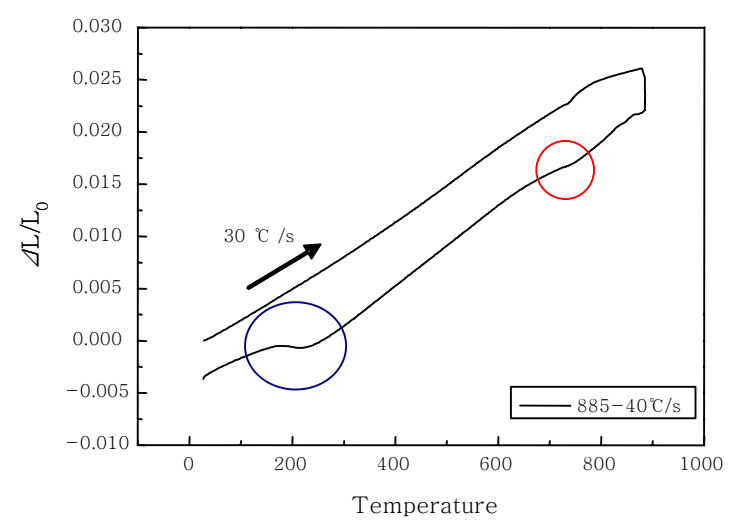

(a)

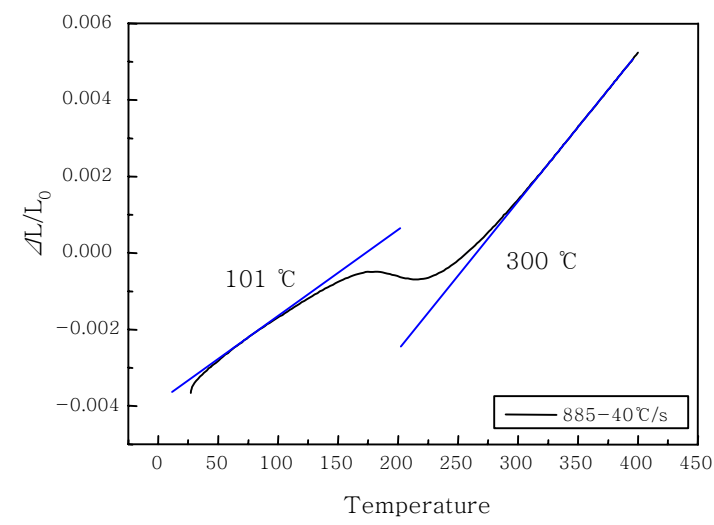

(b)

Fig. 1 Dilitation of continuous cooling from intercritical annealing $\left(885^{\circ} \mathrm{C}\right)$; (a) epitaxial ferrite and martensite transformations, (b) an enlarged section of martensite transformation 
para-equilibrium state is maintained during quenching from the intercritical annealing ${ }^{18)}$. The para-equilibrium during quenching permits transfer of interstitial alloy elements and restricts transfer of substitutional alloy elements. During the intercritical annealing step, the slight variation of substitutional concentration may occur in the austenite. Therefore, the epitixial ferrite was produced in some austenites during quenching. Due to the formation of the epitaxial ferrite, the volume fraction of intercritical austenites should decrease and the carbon content in the intercritical austenite should increase. The measured $\mathrm{M}_{\mathrm{s}}\left(300^{\circ} \mathrm{C}\right)$ was lower than the calculated $\mathrm{M}_{\mathrm{s}}\left(403^{\circ} \mathrm{C}\right)$, which was conformed as the carbon content in the intercritical austenite increased.

Fig. 2a shows the representative section of martensite transformation for the one-step Q\&P dilatation (holding for $30 \mathrm{~s})$. The $\mathrm{M}_{\mathrm{s}}$ temperature $\left(298^{\circ} \mathrm{C}\right)$ was mostly same as that for the continuous cooling dilatation $\left(300^{\circ} \mathrm{C}\right)$. The length increment was observed during the holding period at $240^{\circ} \mathrm{C}$ post to the initial quenching. During the last quenching following the holding process, a new $\mathrm{M}_{\mathrm{s}}$

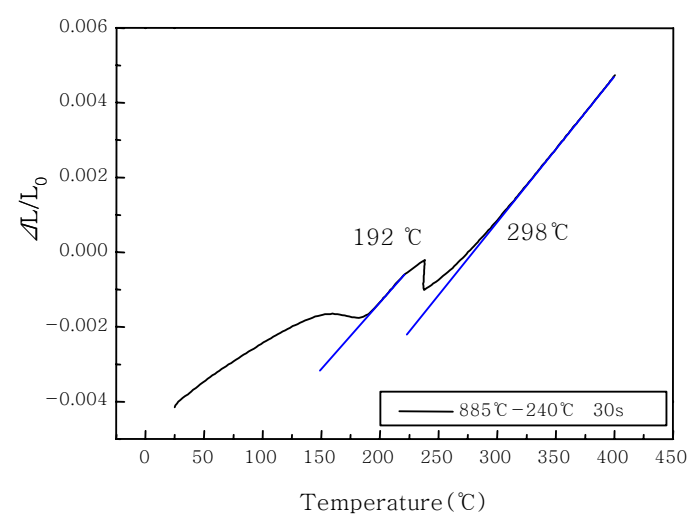

(a)

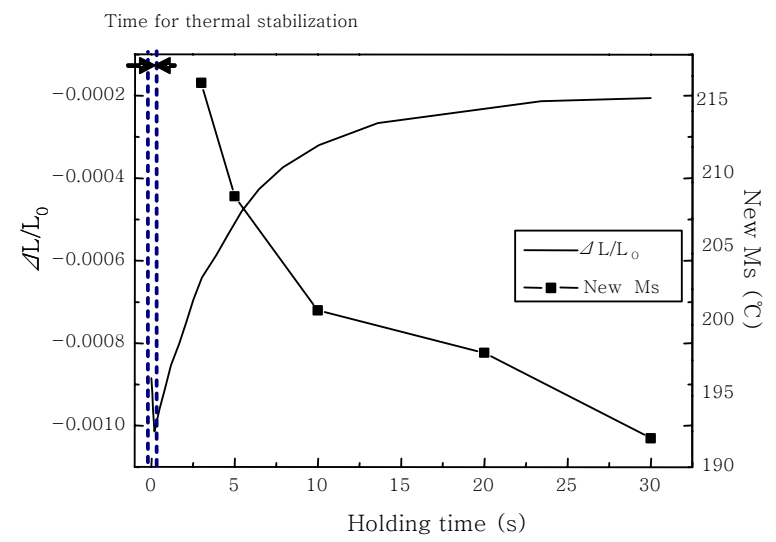

(b)

Fig. 2 Dilatation for one step Q\&P process (initial quenching to $240^{\circ} \mathrm{C}$, followed by holding 30 s at $240^{\circ} \mathrm{C}$ and the final quenching); (a) $\mathrm{M}_{\mathrm{s}}$ obtained from the initial quenching and new $M_{s}$ from the final quenching, (b) a length increment and new $\mathrm{M}_{\mathrm{s}}$ decrease with respect to the holding time temperature was observed and new martensite was produced from the unstable austenite. Speer et al. also found the new $M_{s}$ in the Q\&P steel ${ }^{19)}$. Fig. 2b shows the length increment and the new $\mathrm{M}_{\mathrm{s}}$ decrease as a function of holding time. A dilatometer used in the study needed a duration (less than 1 second) for thermal stabilization in the beginning of holding process, which was not included in the analysis. The length increment during the holding $\left(240^{\circ} \mathrm{C}\right)$ was probably due to the isothermal martensite transformation. The isothermal martensite transformation could occur because the holding temperature was between $\mathrm{M}_{\mathrm{s}}$ and $\mathrm{M}_{\mathrm{f}}$. In the beginning of the holding process, the isothermal martensite was significantly produced because the holding temperature was lower than $\mathrm{M}_{\mathrm{s}}\left(298^{\circ} \mathrm{C}\right)$. As the holding time increased, the new $M_{s}$ decreased since the carbon partitioning from the carbon-enriched martensite to the retained austenite increased the stability of the retained austenite. Therefore, the isothermal bainitic transformation could also occur on the holding of $240^{\circ} \mathrm{C}$ because the holding temperature was larger than the new $\mathrm{M}_{\mathrm{s}}$ in this study. The isothermal martensite/bainite transformation was retarded as the holding time was increased and as the discrepancy between the new $\mathrm{M}_{\mathrm{s}}$ and the holding temperature was increased. A carbon enrichment of the retained austenite during the holding process played a role in decreasing the driving force of the isothermal martensite transformation.

Fig. 3a shows the representative section of martensite transformation for the two-step Q\&P dilatation (holding $5 \mathrm{~s}$ at $240^{\circ} \mathrm{C}$, followed by partitioning at $350^{\circ} \mathrm{C}$ for $1000 \mathrm{~s}$ ). The $\mathrm{M}_{\mathrm{s}}$ temperature $\left(296^{\circ} \mathrm{C}\right)$ was mostly same as that for the continuous cooling dilatation $\left(300^{\circ} \mathrm{C}\right)$. The length increment was observed during the holding period at $240^{\circ} \mathrm{C}$ and the partitioning period at $350^{\circ} \mathrm{C}$. During the final quenching following the partitioning process, a new $\mathrm{M}_{\mathrm{s}}$ was observed and new martensite was produced from the unstable austenite. However, as the partitioning time increased, the new $\mathrm{M}_{\mathrm{s}}$ decreased and disappeared completely when the partitioning at $350^{\circ} \mathrm{C}$ proceeded for $1000 \mathrm{~s}$ following the holding $5 \mathrm{~s}$ at $240^{\circ} \mathrm{C}$ (Fig. 3a). Increasing the partitioning time, the carbon enrichment in the retained austenite should increase, therefore enhancing the stability of the retained austenite and reducing the $M_{s}$.

Fig. $3 b$ shows the length increment and the new $M_{s}$ decrement as a function of partitioning time. An isothermal length increment generated for the partitioning step was probably due to bainite transformation because the partitioning temperature was higher than the $\mathrm{M}_{\mathrm{s}}$ and new $M_{s}$. The isothermal bainite transformation indicated a different behavior as compared with the iso- 


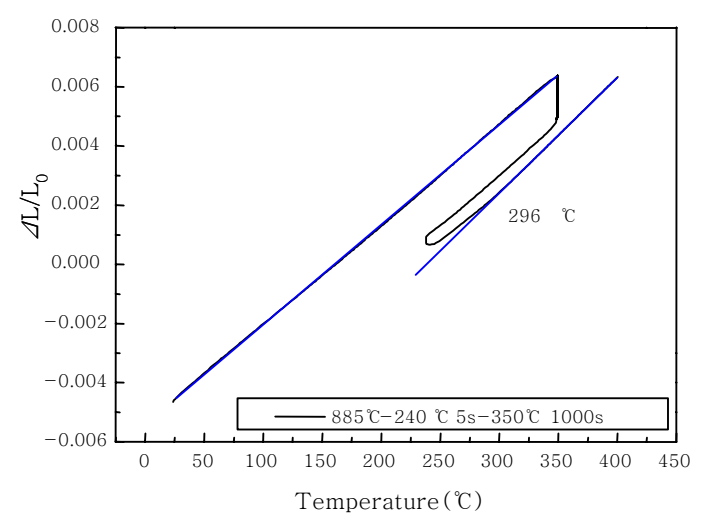

(a)

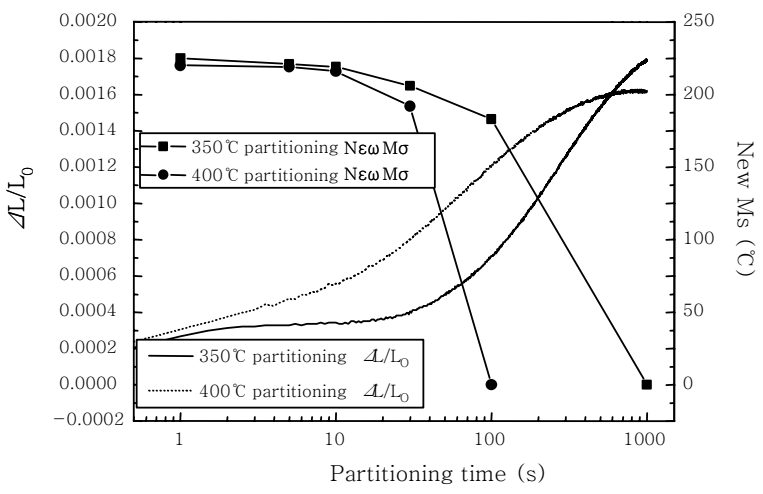

(b)

Fig. 3 Dilatation for two step Q\&P process (initial quenching to $240^{\circ} \mathrm{C}$, followed by holding $5 \mathrm{~s}$ at $240^{\circ} \mathrm{C}$, by partitioning at 350 and $400{ }^{\circ} \mathrm{C}$, and by the final quenching); (a) $\mathrm{M}_{\mathrm{s}}$ obtained from the initial quenching and new $\mathrm{M}_{\mathrm{s}}$ disappeared for 1000s partitioning, (b) a length increment and new $\mathrm{M}_{\mathrm{s}}$ decrement with respect to the partitioning time

thermal martensite transformation: The length increment was minimal in the beginning of the partitioning time. However, as the partitioning proceeded to $\sim 30 \mathrm{~s}$, the dilatation showed a significant increment (Fig. 3b). The partitioning time to $\sim 30$ s might be considered as the bainite incubation period ${ }^{20)}$. On the other hand, the isothermal martensite transformation was mostly produced for the holding time less than 10s (Fig. 2b).

In case of the partitioning executed at $400{ }^{\circ} \mathrm{C}$ post to the holding at $240^{\circ} \mathrm{C}$, the new $\mathrm{M}_{\mathrm{s}}$ dropped more quickly than the case of $350^{\circ} \mathrm{C}$ partitioning (Fig. 3b). The partitioning at $400^{\circ} \mathrm{C}$ should acquire the larger thermal driving force for carbon partitioning than the $350^{\circ} \mathrm{C}$ partitioning. Therefore, the $400^{\circ} \mathrm{C}$ partitioning indicated the shorter incubation period for the bainite transformation than the $350^{\circ} \mathrm{C}$ partitioning. The isothermal bainite transformation was retarded as the partitioning time was increased to $\sim 400$ s. A quick drop of $\mathrm{M}_{\mathrm{s}}$ and short period of bainite incubation for the $400^{\circ} \mathrm{C}$ partitioning steel were the direct evidence of significant effects of carbon partitioning on the stability of retained austenite ${ }^{21)}$.

Detailed SEM microstructures for one step and two step Q\&P steels are depicted in Fig. 4. Blocky martensite shape is certainly appearing as initial quenching, holding process and the final quenching (Fig. 4a). As holding time increased, fine martensite of lath type in blocky martensite increased. The authors suppose that fine martensite of lath type is formed from untransformed austenite by isothermal transformation during holding process. Consequently, the final microstructure is composed to athermal martensite by initial quenching, isothermal martensite/bainite by holding and new martensite (athermal martensite) by the final quenching.

Blocky martensite of $350^{\circ} \mathrm{C}$ partitioned specimen decreased in contrast with the specimens partitioned at $240^{\circ} \mathrm{C}$. This is due to that remained untransformed aus-

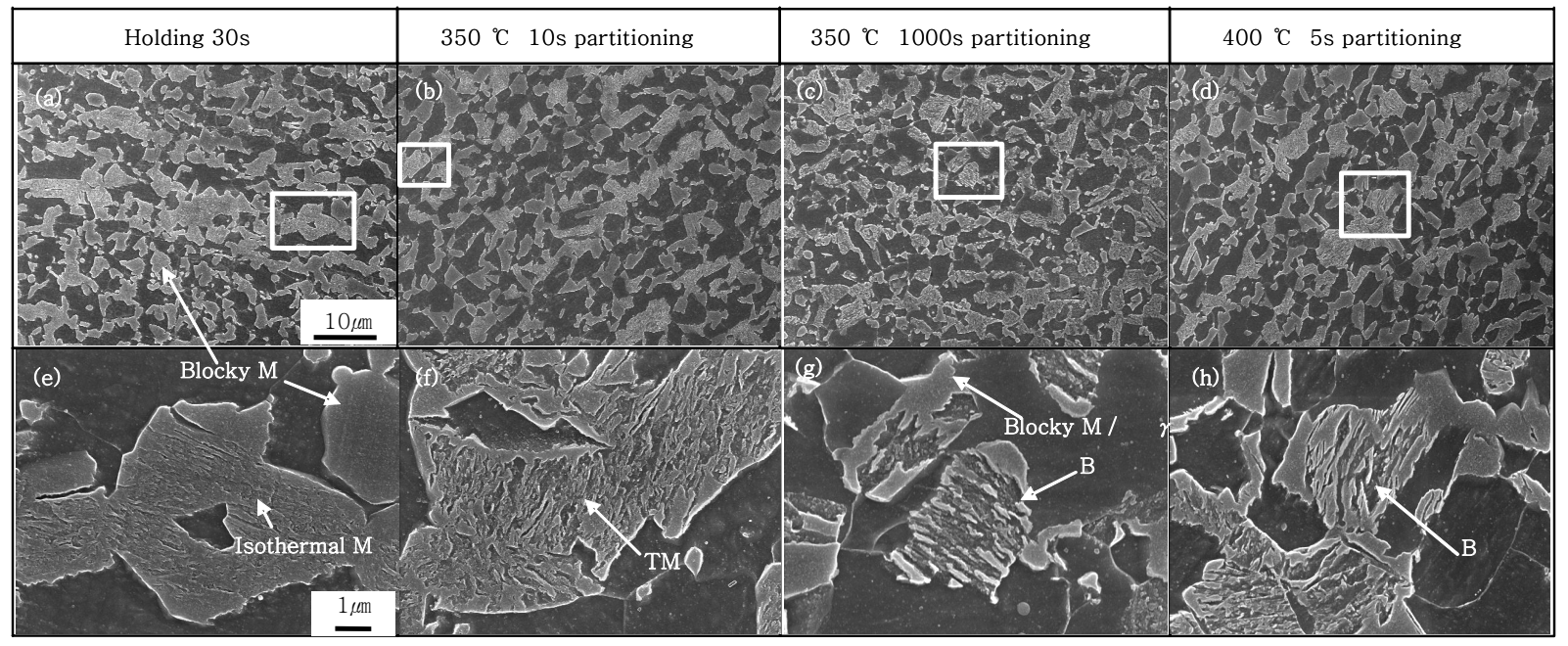

Fig. 4 Microstructure of Q\&P steels as a function of heat treatment conditions: (a,e) 30 s holding at $240^{\circ} \mathrm{C}$, (b,f) $10 \mathrm{~s}$ partitioning at $350^{\circ} \mathrm{C}$ post to holding $5 \mathrm{~s}$ at $240{ }^{\circ} \mathrm{C},(\mathrm{c}, \mathrm{g}) 1000 \mathrm{~s}$ partitioning at $350{ }^{\circ} \mathrm{C}$ post to holding $5 \mathrm{~s}$ at $240{ }^{\circ} \mathrm{C},(\mathrm{d}, \mathrm{h})$ 5 s partitioning at $400^{\circ} \mathrm{C}$ post to holding $5 \mathrm{~s}$ at $240{ }^{\circ} \mathrm{C}$ 
tenite was transformed to bainite during partitioning at $350^{\circ} \mathrm{C}$. As partitioning time decreased, blocky martensite and tempered martensite were more frequently observed for $350^{\circ} \mathrm{C}$ partitioning process. In contrast, as partitioning time increased, bainite shape increased (Fig. 4c). As the stability of retained austenite increased by carbon partitioning, athermal martensite transformation decreased during the final quenching.

In case of $400^{\circ} \mathrm{C}$ partitioning, bainite transformation occurred even at $5 \mathrm{~s}$ partitioned specimen (Fig. $4 \mathrm{~d}$ ). This is because bainite incubation period effect is disappeared and more rapidly approach to bainite transformation area as partitioning temperature increases. And blocky martensite quantity decreased as compared with $10 \mathrm{~s}$ partitioning for $350^{\circ} \mathrm{C}$. The new martensite transformation decreased as retained austenite stability was more rapidly progressed by carbon partitioning in case of partitioning at higher temperature. Consequently, the final microstructure is composed to athermal martensite by initial quenching, isothermal martensite/bainite by holding process, bainite by partitioning process and new martensite (athermal martensite) by the final quenching.

The study was focused on the phase transformation from the retained austenite to martensite/bainite during the partitioning (one step Q\&P and two step Q\&P) processes with no direct observation of mechanical properties. The amount and stability of retained austenite have an interactive, sometimes independent, relationship with the Q\&P-process condition such as QT, $\mathrm{Ht}, \mathrm{PT}$, and $\mathrm{Pt}^{21,22)}$. Therefore, it is very difficult to estimate the tensile properties directly from the dilatation conditions (QT, Ht, PT, and Pt), as shown in Table 1. The effects of the Q\&P conditions on the mechanical property will be discussed in future study associated with the phase transformation and microstructural behavior.

\section{Conclusion}

Isothermal martensite/bainite transformation occurred during partitioning period for $0.15 \mathrm{C}$ quenching and partitioning (Q\&P) steels. Dilatation for the one step Q\&P process was conducted by initial quenching to $240^{\circ} \mathrm{C}$, followed by holding $30 \mathrm{~s}$ at $240^{\circ} \mathrm{C}$ and the final quenching. Carbon partitioning from supersaturated martensite to untransformed austenite was conducted at the partitioning process and new martensite was formed by the final quenching. The isothermal martensite transformation occurred because the holding temperature was between $\mathrm{M}_{\mathrm{s}}$ and $\mathrm{M}_{\mathrm{f}}$. The isothermally transformed martensite/bainite and the athermally transformed martensite were produced by a loss of retained austenite. Dilatation for the two step Q\&P process was conducted by initial quenching to $240^{\circ} \mathrm{C}$, followed by holding $5 \mathrm{~s}$ at $240^{\circ} \mathrm{C}$, by partitioning at 350 and $400^{\circ} \mathrm{C}$, and by the final quenching. The isothermal bainitic transformation occurred because the partitioning temperature was larger than the $\mathrm{M}_{\mathrm{s}}$. The partitioning at $400^{\circ} \mathrm{C}$ indicated the short incubation period for the bainite transformation than the $350^{\circ} \mathrm{C}$ partitioning. The partitioning at $400^{\circ} \mathrm{C}$ had the larger thermal driving force for carbon partitioning than the $350^{\circ} \mathrm{C}$ partitioning. The isothermally transformed martensite/bainite, a quick drop of $\mathrm{M}_{\mathrm{s}}$, and short period of bainite incubation for the $400^{\circ} \mathrm{C}$ partitioning steel were the direct evidence of significant effects of carbon partitioning on the stability of retained austenite.

\section{Acknowledgments}

This work was supported by a 2-year Research Grant of Pusan National University.

\section{References}

1. J. Mola and B.C. De Cooman, Quenching and partitioning (Q\&P) processing of martensitic stainless steels, Metall. Mater. Trans. A 44 (2013), 946-967

2. Q. Huang, C. Schroder, H. Biermann, O. Volkova, and J. Mola, Influence of martensite fraction on tensile properties of quenched and partitioned (QP) martensitic stainless steel, Steel research Int. 87 (2016), 1082-1094

3. J.G. Speer, D.K. Matlock, B.C. De Cooman and J.G. Schroth, Carbon partitioning into austenite after martensite transformation, Acta Mater. 51 (2003), 2611-2622

4. D.K. Matlock, V.E. Brautigam and J.G. Speer, Application of the quenching and partitioning (Q\&P) process to a medium-carbon, high-Si microalloyed bar steel, Materials Science Forum 426-432, (2003), 1089-1094

5. M.F. Gallagher, J.G. Speer and D.K. Matlock, Effect of annealing temperature on austenite decomposition in a Si-alloyed TRIP steel, Symposium on Austenite Decomposition and Stability, ISS/TMS, Chicago, USA (2003) 563-576

6. S.S. Nayak, R. Anumolu, R.D.K. Misra, K.H. Kim and D.L. Lee, Microstructure-hardness relationship in quenched and partitioned medium-carbon and high-carbon steels containing silicon, Mater. Sci. Eng. 498A (2008), 442-456

7. E. De Moor, S. Lacroix, L. Samek, J. Penning and J.G. Speer, Dilatometric study of the quench and partitioning (Q\&P) process, Proceedings of the 3rd International Conference on Advanced Structural Steels, Gyeongju, Korea (2006) 73

8. D.H. Kim, J.G. Speer, H.S. Kim, and B.C. De Cooman, Observation of an isothermal transformation during quenching and partitioning processing, Metall. Mater. Trans. A 40 (2009), 2048-2060 
9. A.J. Clarke, J.G, Speer, M.K. Miller, R.E. Hackenberg, D.V. Ednomds, D.K. Matlock, F.C. Rizzo, K.D. Clarke, and E. De Moor, Carbon partitioning to austenite from martensite or bainite during the quench and partition (Q\&P) process, A critical assessment, Acta Mater. 56 (2008) 16-22

10. B. Ning, Y. Liu, Q. Shi, Z. Gao and L. Yang, Effects of austenite stabilization on the onset of martensite transformation in T91 steel, J. Mater. Sci. Technol. 24 (2) (2008), 202-206

11. S.V. Radcliffe and E.C. Rollason, The kinetics of the formation of bainite in high-purity iron-carbon alloys, J. Iron Steel Inst. 191 (1959), 56-65

12. D.K. Matlock, J.G. Speer, E. De Moor and P.J. Gibbs, Recent developments in advanced high strength sheets steels for automotive applications, an overview, ESTECH, 15 (1) (2012), 1-12

13. I. Chang, Y. Cho, H. Park and D. So, Importance of fundamental manufacturing technology in the automotive industry and the state of the art welding and joining technology, J. Welding and Joining, 34 (1) (2016), 21-25 (in Korean)

14. J. Lee, H. Lee, M. Kim, J. Seo and J. Kim, Effect of weldbond process on the weldability of $1.2 \mathrm{GPa}$ grade galvannealed TRIP steel for car body manufacturing, J. Welding and Joining,34 (6) (2016), 28-34 (in Korean)

15. K.W. Andrews, Empirical formulae for the calculation of some transformation temperatures, J. Iron Steel Inst. 203 (1965), 721-727
16. J.G. Speer, A.M. Streicher, D.K. Matlock, F. Rizzo and G. Krauss, Quenching and partitioning, a fundamentally new process to create high strength TRIP sheet icrostructures, Symposium on Austenite Decomposition and Stability, ISS/TMS, Chicago, USA (2003), 505-522

17. J.G. Speer, D.V. Edmonds, F.C. Rizzo and D.K. Matlock, Partitioning of carbon from supersaturated plates of ferrite, with application to steel processing and fundamentals of the bainite transformation, Curr. Opin. Solid St. Mater. Sci. 8 (2004), 219-237

18. M.J. Santofimia, L.Zhao and J. Sietsma, Microstructural evolution of a low-carbon steel during application of quenching and partitioning heat treatments after partial austenitization, Metall. Mater. Trans. A 40 (2009), 46-57

19. J.G. Speer, F.C. Rizzo Assuncao, D.K. Matlock and D.V. Edmonds, The "quenching and partitioning" process, Background and recent progress, Mater. Res. 8 (4) (2005), 417-423

20. H.K.D.H. Bhadeshia and R.W.K. Honeycombe, Steels microstructure and properties, Elsevier, UK (2006), 141

21. J. Jin, Y. Park, D. Nam, S. Lee, S. Kim, N. Kang and K. Cho, Comparative analysis of strengthening with respect to microstructural evolution for 0.2 carbon DP, TRIP, Q\&P steels, Kor. J. Mater. Res. 19(6) (2009), 293299 (in Korean)

22. S. Yan, X. Liu, W.J. Liu, T. Liang, B. Zhang, L. Liu and Y. Zhao, Comparative study on microstructure and mechanical properties of a C-Mn-Si steel treated by quenching and partitioning (Q\&P) processes after a full and intercritical austenitization, Mater. Sci. Eng. A 684 (2017), 261-269 